\title{
Presenças imperiosas nas elaborações sobre sigilo profissional nos Códigos de Ética do assistente social de 1947 e 1965
}

Imperious presences in the elaborations on professional secrecy in the social worker Ethics Codes of 1947 and 1965

Charles Toniolo ${ }^{a}$

(D) https://orcid.org/0000-0003-4017-9415

Resumo: Este texto analisa o conteúdo dos artigos que versam sobre o tema do sigilo profissional nos Códigos de Ética Profissional do assistente social de 1947 e 1965.

Palavras-chave: Serviço Social. Sigilo Profissional. Códigos de Ética.
Abstract: This text analyzes the content of articles dealing with the topic of professional secrecy in the social worker Professional Ethics Codes of 1947 and 1965.

Keywords: Social Work. Professional Secrecy. Ethics Codes. 
á foram bastante estudadas as influências que o Serviço Social latino-americano sofreu das perspectivas franco-belga e estadunidense (Castro, 2000; Iamamoto; Carvalho, 2005). A primeira, sob forte inspiração neotomista, pautada no humanismo-cristão; a segunda, calcada no pragmatismo e nas tendências funcionalistas das Ciências Sociais.

As críticas às influências estrangeiras ganharam força a partir do Movimento de Reconceituação do Serviço Social na América Latina, em um contexto de intenso questionamento às investidas imperialistas dos Estados Unidos da América (EUA) e dos países da Europa ocidental no continente (Netto, 2005). Seu marco foi o Seminário Regional de Porto Alegre, ocorrido em maio de 1965, nos mesmos mês e ano em que o Conselho Federal de Assistentes Sociais (CFAS) aprovou o Código de Ética Profissional que operacionalizava suas atribuições como órgão fiscalizador do exercício profissional. Porém, o Serviço Social brasileiro já dispunha de um Código que, ainda que não tivesse valor jurídico-administrativo, funcionava como um norteador ético-moral para os profissionais no contexto de organização política da categoria quando de seu surgimento: aquele aprovado em 1947 pela ABAS (Associação Brasileira de Assistentes Sociais), como resultado do protagonismo da Igreja católica nos rumos teóricos e políticos do Serviço Social no Brasil, resultando em uma forte inspiração neotomista de seu conteúdo (Barroco, 2007). Desse modo, por suas naturezas e contextos históricos, ambos os Códigos representam um grau de pioneirismo.

E neles, podemos encontrar artigos que se referem ao tema do sigilo profissional, pois, como lembraram Alonso (2006) e Fernandes (2018), esse é um tema sempre presente nos códigos de ética das profissões. Isso inclui as chamadas "profissões imperiais" - Medicina, Advocacia e Engenharia -, que se constituíram durante o período do Império e tiveram protagonismo nos eventos que engendraram a passagem e 0 desenvolvimento da República até 1930 (Coelho, 1999). Consideradas "profissões liberais" (termo herdeiro da ideia romana de profissão como 
atividade de homens livres para estabelecerem relações com clientes de compra e venda de serviços), elas foram pioneiras tanto no processo de organizações profissionais como de regulamentação e aprovação de códigos de ética no país.

Sobre o sigilo profissional no Serviço Social, Sampaio e Rodrigues (2014), Fernandes (2018) e outros já identificaram a alternância do uso dos termos "sigilo" e "segredo" na trajetória dos Códigos de Ética no Brasil. E a identificamos também entre os dois códigos aqui analisados. Mas além dessas e de outras diferenças, há também surpreendentes semelhanças.

\section{O tema do sigilo profissional no Código de Ética Profissional da ABAS (1947)}

A primeira referência que pode ser encontrada sobre o tema do sigilo na literatura profissional é a sistematização de Pinheiro (1939) sobre os resultados dos debates realizados nas Jornadas Internacionais de Estudos para Assistentes de Serviço Social, em Paris, em 1937. A tônica das reflexões seguia uma série de pressupostos que se remetiam diretamente a uma concepção (neo)tomista de "segredo" e sua aplicação no Serviço Social. Assim, a todo momento, a autora se reporta à questão usando a terminologia "segredo profissional", pois todo o debate francês se deu em torno do secret professionnel, até pelo fato de que o termo "sigilo" não encontra correspondente em língua francesa: ${ }^{1}$ o termo utilizado é sempre "secret".

É também o termo "segredo" que aparece no primeiro artigo que faz menção ao tema do sigilo na revista Serviço Social, de autoria de Vieira (1945). Mesmo com forte influência da perspectiva estadunidense do Confidential Exchange (Richmond, 1917) e com a consagrada utilização

1 De acordo com o dicionário de língua francesa, o termo sigil está no campo semântico das derivações da palavra latina sigillum, mas ele é utilizado em francês apenas ao se referir a sinetes "mágicos", "misteriosos". 
do termo "confidentiality" no Serviço Social dos EUA, a autora utiliza "segredo" - consagrando aqui o uso da terminologia de origem franco-belga. ${ }^{2}$ E também se manifestou na moção de sua autoria junto a outras assistentes sociais apresentada no I Congresso Brasileiro de Serviço Social, em fevereiro de 1947, e que consta na transcrição feita no artigo de Ferreira (1948, p. 45-46):

2. Considerando que: $O$ segredo profissional é uma instituição de grande alcance social, destinada a manter a confiança dos clientes nos profissionais a que se dirigem, por conseguinte, a manter o prestígio das diversas profissões tão necessário para a justiça e a paz sociais, recomenda que seja o segredo profissional mantido escrupulosamente pelos Assistentes Sociais no exercício da profissão.

A própria existência da deliberação congressual representa que, de alguma maneira, o tema se mostrou relevante para os participantes do evento. É possível identificar a categoria "confiança" e o entendimento de uma importância "prestigiosa" do papel das profissões e seus preceitos ético-morais para o alcance de determinado projeto social. Profissões, confiança e valores morais andam juntos na defesa que os participantes do Congresso fizeram do "segredo profissional". Mas essa motivação também pode ser explicada a partir da publicação da tese de Romeu Dale, um frei que apresentou um texto no evento para discussão exatamente sobre a temática, intitulado $O$ segredo profissional. $O$ texto da moção do que é o "segredo profissional" foi extraído literalmente da "Conclusão" de sua tese (Dale, 1947, p. 349). De modo mais bem elaborado e trazendo novos elementos, também o autor se referencia nas formulações neotomistas, na mesma linha da que foi apresentada por Pinheiro (1939); porém, ele usa, ainda que pouquíssimas vezes, a palavra "sigilo".

Portanto, havia na bibliografia profissional (e na legislação brasileira) uma quase absoluta predominância do uso da palavra "segredo"

2 Boa parte da população belga, incluindo a capital Bruxelas, é francófona. 
e os conteúdos a ela pertinentes - além de ser o termo utilizado pela bibliografia francesa à época, a principal influência no Serviço Social brasileiro. Nos EUA, que em 1947 já exercia alguma ascendência, o termo dominante era "confidencialidade". Todavia, o Código aprovado pela ABAS, cinco meses depois da realização do Congresso que ela ajudou a organizar, diz que é dever do assistente social: “

Guardar rigoroso sigilo, mesmo em depoimentos judiciais, sôbre o que saiba em razão de seu ofício" (ABAS, 1948, p. 41, grifo nosso).

A formulação da redação final do Código é curiosa também porque não existiam na bibliografia brasileira quaisquer menções aos temas dos depoimentos judiciais feitos por assistentes sociais.

Para além das diferenças terminológicas, descartamos tanto a influência francesa - que só aprovou o Código de Deontologia em 1950 - como a belga - que teve o seu primeiro Código aprovado somente em 1968 (Barroco, 2007), e também a dos EUA — já que Biestek (1980) fala da aprovação do Código lá no ano de 1947, mas tendo sido o mais provável o de 1949 (AASW, 1949).

Localizamos então o texto do Código de Ética Profissional aprovado pela OAB em 1934 sobre o que cumpre ao advogado no campo dos seus deveres.

guardar sigilo, mesmo em depoimento judicial, sobre o que saiba em razão de seu ofício (OAB, 1978, p. 536).

Assim, como se vê, a redação do Código Ética Profissional do Assistente Social de 1947 é idêntica à do Código dos Advogados vigente à época, exceto pela palavra "rigoroso", que adjetivou o sigilo no texto do Serviço Social.

Enfim, o que concluímos é que a escolha realizada pelo coletivo de assistentes sociais que aprovou o primeiro Código de Ética Profissional foi 
não a de utilizar o pequeno acúmulo de discussões já existente sobre sigilo profissional, mas a de copiar um texto de uma das profissões imperiais. E nos parece que apenas o adjetivo "rigoroso" expressou as produções do Serviço Social do período: a marca da rigidez da moralidade religiosa.

\section{O tema do sigilo profissional na regulamentação ética do Serviço Social brasileiro (1965)}

O primeiro ponto de partida se relaciona com os referenciais filosóficos e teóricos que foram apropriados para fundamentar o Código de Ética Profissional de 1965 de maneira geral (Barroco, 2007) e que guardavam profundas relações entre si: a influência da perspectiva estadunidense do Serviço Social de caráter funcionalista; a ideologia desenvolvimentista e os preceitos liberais que a sustentavam; e as elaborações da Doutrina Social da Igreja sob as bases neotomistas. A pesquisa de Castro (2000) nos mostra que a grande maioria dos cursos de Serviço Social na América Latina surgiu pela iniciativa da UCISS (União Católica Internacional de Serviço Social), sob a hegemonia da Igreja católica e protagonismo franco-belga. E que eles foram igualmente influenciados pelos EUA após o projeto do pan-americanismo monroísta ter se consolidado no continente como uma das estratégias do grande capital imperialista no cenário da Guerra Fria, e ter protagonizado, junto aos organismos internacionais, a expansão profissional pela via dos programas e projetos de Desenvolvimento de Comunidade. Outra vertente seria a intensificação da influência do Serviço Social estadunidense no Brasil; mas a palavra "confidencialidade" sequer aparece na redação do Código de Ética de 1965. ${ }^{3}$ Já com relação ao neotomismo, havia o poderoso debate do Serviço Social francês e os elementos que constavam no Código Moral da UCISS, do qual o Brasil foi um grande entusiasta, ao ponto de a ABESS

3 Aliás, o Código vigente à época nos EUA (aprovado em 1960) citava apenas o direito à privacidade que o assistente social deveria respeitar (NASW, [1960]). 
(Associação Brasileira de Escolas de Serviço Social) publicá-lo em português (Heylen, 1962) poucos anos antes da aprovação do Código de Ética pelo CFAS. E, nesse sentido, parece ser coerente com o que vimos até aqui: foi a concepção neotomista de sigilo profissional que deu as bases para todas as reflexões sobre a questão que se desenvolveram no Serviço Social brasileiro até 1965.

O segundo ponto de partida que adotamos é a própria diferença da natureza desse Código. Trata-se este do primeiro formulado após a regulamentação da profissão no país (Brasil, 1989a; 1989b). Com a instituição dos Conselhos Federal e Regionais de Assistentes Sociais, constituiu-se um poder de Estado que era normatizador, disciplinador e fiscalizador do exercício profissional, o que ensejava a existência de um código de ética correspondente - que agora passaria a compor o escopo legal brasileiro pelo reconhecimento oficial de sua aplicabilidade. Tinha o CFAS o desafio de construir um documento que tornar-se-ia uma ferramenta com valor jurídico. O país vivia a plena ebulição do movimento que levou o Estado brasileiro a regulamentar diversas profissões a partir de sua opção política de regulação do trabalho de um modo geral. Era preciso construir, na prática, um texto completamente novo para o Serviço Social. O Serviço Social não era a primeira profissão a ser regulamentada, tampouco a pioneira a ter de construir um código que expressasse sua regulamentação ética.

Desse modo, identificamos que o Conselho Federal de Medicina (CFM) publicou o seu primeiro Código de Ética em 11 de janeiro de 1965 (CFM, [1965]), isto é, quase quatro exatos meses antes da publicação do Código dos assistentes sociais (8 de maio). Mesmo tendo sido criados em 1945, os Conselhos de Medicina só ganhariam o estatuto de autarquias federais em 1957. Contudo, os poderes de fiscalização ética foram incorporados como atribuições dos conselhos profissionais à medida que a própria experiência de regulamentação das profissões foi se desenvolvendo no Brasil - da qual a Medicina foi uma das pioneiras. Assim, o Código dos médicos vigente até janeiro de 1965 era 
aquele que fora aprovado pela Associação Médica Brasileira (AMB), ${ }^{4}$ em 1953 (AMB, [1953]).

No relatório de gestão do ano de 1963, consta a informação de que o CFAS já iniciara o processo de discussão de elaboração do novo Código (CFAS, 1964) - momento este em que o CFM ainda não havia aprovado o seu. Mas o recurso à Medicina pelo Serviço Social se confirma logo no artigo 15, o primeiro que versa sobre o "segredo profissional":

O assistente social é obrigado pela Ética e pela Lei (art. 154 do Código Penal) a guardar segrêdo sobre tôdas as confidências recebidas e fatos de que tenha conhecimento ou haja observado no exercício de sua atividade profissional, obrigando-se a exigir o mesmo segrêdo de todos os seus colaboradores (CFAS, 1965, p. 8).

Vejamos agora a redação do artigo 36 do Código de Deontologia Médica de 1953:

O médico está obrigado, pela ética e pela Lei, a guardar segredo sobre fatos de que tenha conhecimento, por ter visto, ouvido ou deduzido, no exercício de sua atividade profissional, ficando na mesma obrigação todos os seus auxiliares (AMB, [1953]).

Portanto, o Serviço Social brasileiro inicia sua formulação sobre o tema do sigilo profissional em um Código de Ética copiando a redação de um Código de uma profissão imperial. Mas alguns aspectos da redação foram alterados.

Desde a sistematização de Pinheiro (1939), os assistentes sociais reconhecem que os trabalhadores institucionais que prestam serviços administrativos que compõem os setores, turmas, seções, departamentos

4 Assim como no Serviço Social. No período que compreendeu a publicação do Decreto que criou os conselhos de assistentes sociais e a aprovação do Código pelo CFAS, foi vigente o Código da ABAS (Brasil, 1989b). 
de Serviço Social estão também sob a responsabilidade de não revelar as informações que são acessadas pelos profissionais - o que supõe que não existe obrigação de sigilo do assistente social para com esses agentes. No Código dos médicos, o texto também aponta que tais agentes também estão submetidos ao dever de "segredo". No entanto, na versão do CFAS, a redação prevê que é tarefa do assistente social "exigir isso de seus colaboradores". Tal diferença expressa, ao nosso ver, exatamente a diferença da natureza dos dois Códigos. $\mathrm{O}$ da Medicina era vinculado a uma associação profissional, de caráter autônomo; o Código do Serviço Social é uma produção de um conselho profissional — uma instituição ligada ao Estado que possui prerrogativas de fiscalização somente sobre os assistentes sociais (CRESS/7ª REGIÃO, 2017). Um auxiliar administrativo não exerce a profissão de Serviço Social por não possuir registro profissional no respectivo Conselho Regional. Assim, não poderia o CFAS definir a obrigação de sigilo profissional para esses trabalhadores - e estabeleceu, portanto, que é obrigação de assistentes sociais exigirem a extensão da obrigação do sigilo àqueles.

Note-se que foi com a instituição dessa exigência que o conselho de Serviço Social, já em 1965, inaugurou a tendência de usar o poder regulatório sobre o exercício profissional e a conduta dos agentes profissionais para interferir em aspectos que dizem respeito à dinâmica e à estrutura organizacional de uma instituição: dotando os próprios assistentes sociais da responsabilidade de provocar a construção de rotinas e procedimentos institucionais. $O$ que se observa com essa diferença entre os Códigos de Medicina e de Serviço Social é que, ainda que de maneira tímida e pontual, já nos anos 1960 o tema do sigilo profissional é utilizado como um "epifenômeno" para permitir que o assistente social interfira nas dinâmicas burocrático-organizacionais da instituição onde trabalha em razão de aspectos que envolvem suas condições de trabalho.

A segunda diferença diz respeito a uma substituição da qualificação dos dados que deveriam ser mantidos em "segredo". Enquanto no Código da Medicina estava previsto que os dados em questão eram aqueles que 
o profissional de Medicina "viu, ouviu ou deduziu", no do Serviço Social os três verbos foram substituídos por "observar".

As discussões sobre a observação não eram recentes nas Ciências Sociais. Elas ganharam centralidade com o desenvolvimento de metodologias de pesquisas etnográficas no campo da Antropologia (e na Sociologia) - e envolvem uma série de polêmicas que foram sistematizadas por Minayo (2000). E é bastante comum, sobretudo a partir de uma perspectiva positivista, associar a observação a uma técnica "neutra" de coleta de dados sobre a realidade social pelo uso dos sentidos humanos, que podem ter sua capacidade ampliada a partir do uso de instrumentos.

O que podemos aferir é que a adoção do verbo "observar" no lugar de "ver e ouvir" pode ter relação com essa clássica definição. Mas ao não incluir a palavra "deduzir", parece-nos que o Código do CFAS exclui qualquer sentido que esse verbo possa denotar quando pensado na relação com a questão do sigilo, justamente porque o pressuposto de uma "dedução" é, exatamente, a interpretação dos dados que foram coletados pelo profissional pela via da mobilização de diversos instrumentos. $\mathrm{E}$ a interpretação, a emissão de uma opinião profissional, foi um elemento que fez parte do escopo de inquietações no Serviço Social francês (ANAS, 1961) e nos EUA a partir da formulação de Richmond (1917), que associava o estudo social com a necessidade da produção de um diagnóstico. Portanto, ao retirar a "dedução" do texto do Código, o CFAS parece reconhecer que conteúdos de "diagnósticos sociais", ou seja, as interpretações, as conclusões, as explicações, os pareceres construídos pelos assistentes sociais a partir do acesso que têm às informações não são, necessariamente, sigilosos, pois são passíveis de serem comunicados a outros agentes. No entanto, mesmo que a seguir o Código estabeleça os critérios que justifiquem a revelação, mantém o pressuposto do Código dos médicos de que os fatos coletados pelos assistentes sociais são objeto de guarda de "segredo profissional".

Assim, ao copiar o texto do Código da AMB, os assistentes sociais não se atentaram para a sua condição de trabalhadores assalariados e 
fizeram uma transposição acrítica de uma premissa que se aplicava a tradicionais práticas liberais de uma profissão. No caso, a dos médicos - ainda que a condição de assalariamento destes já se espraiasse como resultado na inserção das profissões no marco das próprias relações sociais capitalistas. Tendência já apontada por Marx e Engels (1998) quando analisavam a própria situação que o capitalismo criou para os então chamados "profissionais liberais".

Mas a histórica caracterização das profissões imperiais como liberais, sobretudo aquelas ligadas ao Direito e à Medicina, foi referência importante para a afirmação do estatuto de profissionalidade do Serviço Social no momento em que ele se legitimava, se expandia e lutava por reconhecimento oficial. Os dispositivos legais que regulamentaram o Serviço Social no Brasil (incluindo o Código de 1965) definiam a profissão como liberal. Portanto, parece coerente que o Serviço Social copiasse a premissa de uma profissão que historicamente se legitimou e usufruiu de prestígio ${ }^{5}$ por ser considerada liberal, mesmo que já não o fosse no sentido tradicional que essa concepção carrega.

Uma última observação sobre o caput do artigo 15 do Código de 1965 diz respeito ao fato de, quando comparado ao Código dos médicos, notar-se a inclusão junto ao dever de guardar segredo dos fatos, também, o das "confidências recebidas". O Código Moral de Serviço Social da UCISS já associava "segredo" e "confidência", mas o documento internacional avança ainda para associar justamente a "confidência" com a "confiança", por meio da caracterização do assistente social como um "confidente necessário":

O segrêdo profissional impõe o dever de não revelar os segrêdos que são confiados a certas pessoas apresentadas como confidentes necessários, em razão de sua função. Mesmo que o segrêdo do assistente social não se revista do caráter legal, êle está preso ao segrêdo por motivos de direito

5 Tal como dizia o texto da moção aprovado no I Congresso em 1947. 
natural. $O$ assistente social, recebendo confidências em razão do exercício de suas funções, considere-se prêso ao segrêdo profissional (Heylen, 1962, p. 59, grifos nossos).

Portanto, vê-se com nitidez que o Código de Ética aprovado em 1965 incorporou as reflexões sobre as relações entre "confidência" e sigilo profissional, provenientes, sobretudo, do debate europeu, por via de sua ainda forte vinculação com a Igreja católica e uma profunda apropriação teórico-metodológica dos fundamentos neotomistas.

Até 1965, o que identificamos na bibliografia brasileira que consultamos foi uma influência de elementos do pensamento neotomista - sobretudo em Pinheiro (1939) e em Dale (1947) - sobre a definição do que seria o "segredo" e a classificação dos seus tipos. E essas foram as referências para o Código, pois no parágrafo $1^{\circ}$ do artigo 15 lê-se que:

Tendo em vista exclusivamente impedir um mal maior, será admissível a revelação do segrêdo profissional para evitar um dano grave, injusto e atual ao próprio cliente, ao assistente social, a terceiros e ao bem comum (CFAS, 1965, p. 8-9).

O mesmo se observa quando analisamos os parágrafos seguintes do artigo 15:

$\S 2^{\circ}$ - A revelação só será feita, após terem sido empregados todos os recursos e esforços, para que o próprio cliente se disponha a revelá-lo.

$\S 3^{\circ}$ - A revelação será feita dentro do estritamente necessário o mais discretamente possível, quer em relação ao assunto revelado, quer em relação ao grau e ao número de pessoas que dêle devem tomar conhecimento (CFAS, 1965, p. 9).

Trata-se de temas que fizeram parte das reflexões que foram realizadas pelo Serviço Social brasileiro desde as suas protoformas: o convencimento do usuário a ele mesmo ser o protagonista da revelação 
da informação e o princípio hipocrático da divulgação apenas do que é estritamente necessário ${ }^{6}$ - e estabelecendo alguns critérios sobre os destinatários da comunicação a ser realizada pelo assistente social (grau de compartilhamento e número de pessoas).

Assim, o que se vê é que o Código de Ética de 1965 segue à risca a concepção de segredo sob inspiração neotomista:

- Um ponto de partida de que tudo o que se toma conhecimento no exercício profissional é sigiloso - o que parte da premissa do "direito natural" do segredo como elemento da dignidade da pessoa humana (Pinheiro, 1939; Dale, 1947);

- A partir disso, se estabelecem critérios ético-morais para uma "possível" revelação;

- Diante disso, escolhe-se a forma de construir a revelação;

- Ao final, decide-se sobre o universo que tomará conhecimento do "segredo".

Constatamos, assim, que foi apenas no Código de 1965 que foi incorporado o pequeno acúmulo de discussões sobre a questão do sigilo profissional publicadas no Brasil antes do Código de 1947.

Assim, o trecho anteriormente exposto do Código reforça uma concepção de sigilo profissional que, na esteira do espírito geral do documento, possui fundamentos provenientes do neotomismo. E, ao mesmo tempo, reforça também a concepção de que o Serviço Social é uma profissão liberal, não levando em consideração que a intervenção profissional se realiza em espaços institucionais que lidam com elementos do cotidiano da população atendida, e que neles existe o compartilhamento de informações referentes à intimidade e à vida privada dos usuários.

6 Trata-se do texto que versa sobre a questão do sigilo no Juramento de Hipócrates, um dos textos dos Tratados deontológicos no conjunto dos escritos do médico grego no século V a.C. Diz o texto: "O que vir ou ouvir, durante o tratamento, sobre a vida dos homens, sem relação com o tratamento, e que não for necessário divulgar, calarei, considerando tais coisas como segredos" (Cairus; Ribeiro Júnior, 2005, p. 152-153). 
Esta associação entre "segredo" e "intimidade e vida privada", típica do pensamento liberal burguês, aparece de imediato logo no artigo 16 do Código de 1965, a saber:

Além do segrêdo profissional, ao qual está moral e legalmente sujeito, o assistente social deve guardar discrição no que concerne ao exercício de sua profissão, sobretudo quanto à intimidade das vidas particulares, dos lares e das instituições onde trabalhe (CFAS, 1965, p. 9).

A questão da "discrição" como uma virtude moral de um assistente social já aparecia no debate francês sobre o sigilo, sendo inclusive utilizada no texto final do Código de Deontologia do Serviço Social aprovado em 1950 (ANAS, 1951); também a "discreção" dava o título do item que versava sobre o tema do sigilo profissional no Código da UCISS - lá, como vimos, qualificado como "segredo" (Heylen, 1962).

E é também do Código francês que se tem a associação direta entre discrição, intimidade e vida privada - como resultado, inclusive, de todo o debate moderno que se construiu em torno desses elementos, sobretudo após o seu reconhecimento como direitos na Declaração Universal dos Direitos Humanos (ONU, [1948]). Diz o Código aprovado pela associação francesa em 1950:

Além do segredo profissional a que está legalmente obrigado, o assistente social deve demonstrar discrição e delicadeza por tudo o que diz respeito à intimidade da vida privada e dos lares (ANAS, 1951, p. 671, tradução nossa).?

Não restam dúvidas de que o texto do referido artigo 16 do Código de Ética brasileiro de 1965 é uma cópia da redação do Código do Serviço Social francês, com pequenas alterações.

Tradução livre de: "En dehors même du secret professionnel auquel ele est légalement astreinte, l'assistante sociale doit faire preuve de discrétion et de délicatesse pour tout ce qui concerne l'intimité des viés privées et des foyers". 
A primeira delas foi a inclusão do termo "moral" no texto brasileiro como uma das obrigações que envolvem o "segredo" profissional - no original francês, consta apenas a dimensão "legal”. Para nós, essa diferença pode ser explicada não apenas em razão de que o tema do sigilo foi tratado até então pelos assistentes sociais brasileiros no campo da moralidade profissional - porque ele também assim o foi na França. Mais do que isso, a diferença está na natureza dos Códigos e nas histórias políticas que a profissão vivia nos dois países.

Apesar de o Serviço Social ter sido regulamentado na França em 1946, lá não se instituiu nenhum dispositivo jurídico-institucional de disciplinamento e controle do exercício da profissão. Assim como o da ABAS, o Código de Deontologia francês tinha somente valor ético-moral — o dever de sigilo profissional estava juridicamente regulado na França apenas do ponto de vista legal e no campo penal. ${ }^{8}$ Um dos objetivos com a aprovação do Código era continuar a mobilização para a instituição de uma ordem profissional na França (Pascal, 2012). Portanto, referenciar-se à legislação vigente no texto do Código poderia ser uma estratégia importante, no sentido de demonstrar o reconhecimento que a profissão tinha do arcabouço jurídico existente na França e, assim, usar tal argumento para sensibilizar as instâncias decisórias do Estado francês de que a existência de um órgão fiscalizador não substituiria a soberania estatal no campo das decisões penais referentes ao crime de violação de secret professionnel.

O Código brasileiro era de outra natureza. Sua própria existência do dever de "segredo profissional" que ele previa já submetia legalmente os assistentes sociais - além dos dispositivos que existiam na legislação brasileira. Assim, parece que a inclusão do termo "moral" diz respeito justamente à afirmação dessa dimensão do sigilo profissional para além do jurídico.

8 De acordo com o dicionário de tradução on-line Linguee, o termo astreinte em língua francesa pode denotar "sanção". 
Sobre o termo délicatesse (delicadeza) quando da abordagem profissional, uma virtude moral que sempre foi requerida aos assistentes sociais, não nos parece ser sua supressão uma questão central, dado o próprio caráter formal que o texto do Código de 1965 deveria apresentar. Mas não deixa de chamar nossa atenção que tal retirada tenha ocorrido justamente no momento político brasileiro em que se recrudesciam as ações truculentas e repressivas do Estado em razão dos desdobramentos do golpe empresarial-militar de 1964 (Netto, 2004).

Entretanto, o texto brasileiro alterou o predicado de "guardar discrição": enquanto o francês dizia "por tudo o que diz respeito à intimidade da vida privada e dos lares", o Código aprovado pelo CFAS falava que era "no que concerne ao exercício de sua profissão, sobretudo quanto à intimidade das vidas particulares, dos lares e das instituições onde trabalhe".

Notamos, em primeiro lugar, que os brasileiros ampliaram o escopo da necessidade de guardar discrição, não apenas (mas sobretudo) no que diz respeito à intimidade, à vida privada e aos lares: o universo da discrição eram todos os aspectos que envolvem o exercício profissional. Parece-nos, portanto, que essa afirmação era necessária pela inclusão que foi feita no Código brasileiro quando comparado ao francês: a discrição também deveria se dar sobre aspectos que envolviam a instituição na qual trabalhava o assistente social. Isso pode evidenciar cabalmente $o$ posicionamento político adotado para a elaboração do Código de Ética. Se ocultar informações sobre a instituição - especialmente as públicas - à população usuária, a outras instituições ou à população em geral é dificultar a participação, e a gestão, e o acesso democrático a ela, parece-nos que regular o dever de sigilo sobre informações concernentes à instituição sintonizava-se essencialmente com o projeto centralizador $e$ autoritário do Estado brasileiro instituído a partir do golpe de 1964.

Esse dado reforça a hipótese de que o Código de 1965, mais do que uma consequência "natural" do processo de regulamentação da profissão, foi também uma reação aos movimentos críticos da categoria que se articularam na primeira metade dos anos 1960, assim como uma reafirmação 
dos compromissos políticos conservadores que eram a marca do Serviço Social brasileiro. Para tanto, já sinaliza elementos modernizantes, que vieram tanto com a influência estadunidense como com o desenvolvimentismo, mas que se consolida justamente no decurso da ditadura empresarial-militar pós-1964 (Netto, 2004).

Por fim, aparecia um artigo que tratava da relação entre o sigilo profissional do assistente social com o sistema de justiça — o que também estava disposto no Código de 1947 ao falar do depoimento judicial, como uma transcrição do Código da OAB. A formulação de 1965 é mais elaborada:

Art. 17. O assistente social não se obriga a depor como testemunha, sôbre fatos de que tenha conhecimento profissional, mas intimado a prestar depoimento, deverá comparecer perante à autoridade competente para declarar-lhe que está ligado à obrigação do segrêdo profissional, de acordo com o art. 144 do Código Civil (CFAS, 1965, p. 9).

Contudo, lê-se no artigo. 37 do Código de Deontologia Médica de 1953:

O médico não revelará, como testemunha, fatos de que tenha tido conhecimento no exercício de sua profissão; mas, intimado a prestar depoimento, em casos dessa natureza, deve comparecer perante a autoridade que o mandou intimar, para declarar-lhe que está ligado à obrigação do segredo profissional (AMB, [1953]).

As diferenças terminológicas entre os Códigos do Serviço Social de 1965 e da Medicina de 1953 são irrelevantes nesse caso. O crucial é novamente a constatação de que a redação do artigo 17 foi uma reprodução do texto do Código dos médicos.

\section{Considerações finais}

Por mais que os debates sobre o sigilo profissional no Serviço Social que foram construídos sob a inspiração neotomista tivessem algum grau 
de profundidade teórico-filosófica, eles foram bastante incipientes no Brasil até o momento de regulamentação ética da profissão. E, fiel ao próprio neotomismo como uma corrente filosófica ligada ao pensamento social e religioso, parte de uma formulação abstrata de pessoa humana e de sociedade, descolada das condições materiais concretas que seres humanos estabelecem e criam em suas relações cotidianas, marcadas pela exploração, dominação e opressão de classes e segmentos de classes: também por isso, acaba se constituindo como um pensamento no campo do conservadorismo, político e moral (Barroco, 2007). Isso refrata diretamente na questão do sigilo profissional.

O balanço do período compreendido entre o surgimento do Serviço Social no Brasil e sua regulamentação ética acerca do debate que envolvia o sigilo profissional é a de que ele se deu a partir de dois vetores centrais: a necessidade de afirmação de seu estatuto de profissionalidade, buscando referências nas profissões já consolidadas e consideradas "liberais"; e as influências franco-belga e estadunidense que a profissão sofreu no Brasil, especialmente daquelas formulações pautadas no neotomismo, protagonizadas pelo debate europeu. Assim, os textos sobre o tema do sigilo nos Códigos de Ética Profissional do Assistente Social de 1947 e de 1965 estão cabalmente marcados por presenças "imperiosas": do imperialismo europeu (o Serviço Social francês) e de profissões imperiais (Advocacia e Medicina).

E esse é um exemplo de como o termo "profissões imperiais" pode ganhar outro sentido para além daquele apresentado por Coelho (1999). É o caso, por exemplo, da interpretação construída por Vargas (2010, p.109):

No caso brasileiro se pode associar, para além do prestígio universal e perene dos médicos, a constituição e a sustentação mesma do Estado ao apoio dos dois outros grupos profissionais aqui tratados: os bacharéis no Brasil colônia, os engenheiros imprescindíveis aos movimentos de industrialização e novamente os advogados na transição do terceiro milênio, dentro do fenômeno da judicialização das relações sociais [...]. 
Se a história do Serviço Social no Brasil até 1965 foi marcada por influências de produções realizadas em países de capitalismo central, mas também cujas emergência e legitimação foram alavancadas pela Medicina e pelo Direito - como uma profissão que lhes pudesse ser "auxiliar", conferindo-lhe uma determinada condição de "subalternidade profissional" (Iamamoto; Carvalho, 2005) —, os textos sobre o tema do sigilo profissional nos dois primeiros Códigos não deixam dúvidas: na esteira de afirmar seu estatuto de profissionalidade, o Serviço Social brasileiro optou por redações que, na prática, revelam essa mesma subalternidade nas presenças "imperiosas" das profissões imperiais (Medicina e Direito) e do imperialismo europeu (Serviço Social francês).

\section{Referências}

AASW. The 1949 Delegate Conference. Social Work Journal, Nova Iorque: AASW, v. XXX, n. 4, out. 1949.

ABAS. Código de Ética Profissional dos Assistentes Sociais. Organização: Francisco de Paula Ferreira. Serviço Social, São Paulo, n. 48, p. 41-44, mar./jun. 1948.

ALONSO, Augusto Hortal. Ética das profissões. Tradução: Silvana Cobucci Leite. São Paulo: Loyola, 2006.

AMB. Código de Ética da Associação Médica Brasileira. [1953]. Disponível em: https:// portal.cfm.org.br/images/stories/documentos/EticaMedica/codigoeticaamb1953.pdf. Acesso em: 22 jul. 2019.

ANAS. Presentation et adoption du Code de Déontologie au cours de l'Assemblée Générale. Feuillets, Paris: ANAS, p. 13-15, jan. 1951.

ANAS (org.). Déontologie. Paris: ANAS, 1961.

BARROCO, Maria Lúcia Silva. Ética e Serviço Social: fundamentos ontológicos. 5. ed. São Paulo: Cortez, 2007.

BIESTEK, Félix P. O relacionamento em Serviço Social de casos. Tradução: Mercedes Marchant. Porto Alegre: PUC/RS, 1980.

BRASIL. Lei Federal n. 3.252, de 27 de agosto de 1957. In: VIEIRA, Balbina Ottoni (org.). História do Serviço Social. 5. ed. Rio de Janeiro: Agir, 1989a. 
BRASIL. Decreto-lei n. 994, de 15 de maio de 1962. In: VIEIRA, Balbina Ottoni (org.). História do Serviço Social. 5. ed. Rio de Janeiro: Agir, 1989b.

CAIRUS, Henrique F.; RIBEIRO JÚNIOR, Wilson A. Textos hipocráticos: o doente, o médico e a doença. Rio de Janeiro: Fiocruz, 2005.

CASTRO, Manuel Manrique. História do Serviço Social na América Latina. 5. ed. revis. Tradução: José Paulo Netto e Balkys Villalobos. São Paulo: Cortez, 2000.

CFAS. $1^{\circ}$ relatório de atividades: 1963. Rio de Janeiro: CFAS, 1964.

CFAS. Código de Ética Profissional do Assistente Social. Rio de Janeiro: CFAS, 1965.

CFM. Código de Ética Médica. [1965]. Disponível em: http://portal.cfm.org.br/images/ stories/documentos/EticaMedica/codigoeticamedica1965.pdf. Acesso em: 22 jul. 2019.

COELHO, Edmundo Campos. As profissões imperiais: medicina, engenharia e advocacia no Rio de Janeiro. 1822-1930. Rio de Janeiro: Record, 1999.

CRESS/7ª REGIÃO (org.). CRESS $\neq$ sindicatos: diferenças das atribuições entre conselhos profissionais e sindicatos. Rio de Janeiro: CRESS/7ª Região, 2017.

DALE, Romeu. O segredo profissional. In: CONGRESSO BRASILEIRO DE SERVIÇO SOCIAL, 1., 1947, São Paulo. Anais [...]. São Paulo: CEAS, 1947. p. 336-350.

FERNANDES, Neide A. Sigilo e ética do/a assistente social. São Paulo: Cortez, 2018.

FERREIRA, Francisco de Paula. O Serviço Social e a organização profissional. Apêndice: Código de Ética Profissional dos Assistentes Sociais. Serviço Social, São Paulo, n. 48, p. 31-44, mar./jun. 1948.

HEYLEN, Cônego V. Código de moral do Serviço Social. Tradução: Beatriz Guerra de Aguiar Vallin. São Paulo: Herder, 1962.

IAMAMOTO, Marilda Vilela; CARVALHO, Raul de. Relações sociais e Serviço Social no Brasil: esboço de uma interpretação histórico-metodológica. 17. ed. São Paulo: Cortez; Lima: CELATS, 2005.

MARX, Karl; ENGELS, Friedrich. O manifesto comunista. Tradução: Maria Lucia Como. 14. ed. Rio de Janeiro: Paz e Terra, 1998.

MINAYO, Maria Cecília de Souza. O desafio do conhecimento: pesquisa qualitativa em saúde. São Paulo: Hucitec; Rio de Janeiro: Abrasco, 2000.

NATIONAL ASSOCIATION OF SOCIAL WORKERS (NASW). Code of Ethics. [1960]. Disponível em: https://www.socialworkers.org/About/Ethics/Code-of-Ethics/g/LinkClick. aspx?fileticket=lPpjxmAsCTs\%3d\&portalid=0. Acesso em: 29 jan. 2019. 
NETTO, José Paulo. Ditadura e Serviço Social: uma análise do Serviço Social no Brasil pós-64. 7. ed. São Paulo, Cortez, 2004.

NETTO, José Paulo. O movimento de reconceituação - 40 anos depois. Serviço Social \& Sociedade, São Paulo: Cortez, n. 84, p. 5-19, 2005.

OAB. Código de Ética Profissional. Organização: Eugênio R. Haddock Lobo e Francisco Costa Netto. Comentários ao Estatuto da $O A B$ e às regras da profissão do advogado. Rio de Janeiro: Imprenta, 1978.

ONU. Declaração Universal dos Direitos Humanos. [1948]. Disponível em: https://www. ohchr.org/EN/UDHR/Pages/Language.aspx?LangID=por. Acesso em: 22 jul. 2019.

PASCAL, Henri. La construction de l'identité professionnelle des assistentes sociales: l'Association Nationale des assistentes sociales (1944-1950). Paris: L'École des Hautes Études em Santé Publique, 2012.

PINHEIRO, Maria Esolina. Serviço Social: infância e juventude desvalidas. Aplicações. Formas. Técnicas. Legislação. Rio de Janeiro: A. Coelho Branco Filho, 1939.

RICHMOND, Mary Ellen. Social diagnosis. Nova York: Russel Sage Foundation, 1917.

SAMPAIO, Simone Sobral; RODRIGUES, Filipe Wingeter. Ética e sigilo profissional. Serviço Social \& Sociedade, São Paulo: Cortez, n. 117, p. 84-93, jan./mar. 2014.

VARGAS, Hustana Maria. Sem perder a majestade: "profissões imperais" no Brasil. Estudos de Sociologia, Araraquara: Unesp, v. 15, n. 28, p. 107-124, 2010.

VIEIRA, Balbina Ottoni. Um meio de colaboração entre serviços sociais: o fichário central de assistidos. Serviço Social, São Paulo: n. 36, p. 157-167, mar. 1945.

\section{Sobre o autor}

Charles Toniolo - Doutor em Serviço Social. Professor adjunto do Departamento de Fundamentos do Serviço Social.

E-mail: charlestoniolo@yahoo.com.br 